RESEARCH REPORT

\title{
Income as mediator of the effect of occupation on the risk of myocardial infarction: does the income measurement matter?
}

\author{
Ingelise Andersen, Michael Gamborg, Merete Osler, Eva Prescott, Finn Diderichsen
}

J Epidemiol Community Health 2005;59:1080-1085. doi: 10.1136/jech.2005.036848

See end of article for
authors' affiliations
....................
Correspondence to:
Mrs I Andersen, Institute of
Preventive Medicine,
Danish Epidemiology
Science Centre, H:S
Kommunehospitalet, DK-
1399 Copenhagen,
Denmark; ia@ipm.hosp.dk
Accepted for publication
14 June 2005

\begin{abstract}
Aim: To investigate whether the effect of occupational grade on the risk of myocardial infarction (MI) is mediated by income with different aspects of income taken into account.

Methods: Data were used from three prospective population studies conducted in Copenhagen. A total of 16665 employees, 43\% women, aged 20-75 years, with an initial examination between 1974 and 1992 were followed up until 1999 for incident (hospital admission or fatal) MI. Register based information on job categories and income was used.

Results: During follow up, 855 subjects were diagnosed with a MI: 708 men and 147 women (in total $47 \%$ fatal). The hazards by household and individual income showed a graded effect with a hazard ratio (HR) of 1.43 (95\% Cl 1.12 tol .83) for the lowest household income group compared with the highest, whereas equivalent income showed an inverse "J shape" effect with a HR of $1.55(95 \% \mathrm{Cl} 1.25$ to 1.82) for the third income group compared with the highest. HR for unskilled workers as compared with executive managers was reduced from $1.55(95 \% \mathrm{Cl} 1.24$ to 1.93$)$ to $1.42(95 \% \mathrm{Cl} 1.12$ to 1.81$)$ after adjustment for household income.

Conclusions: Occupation and income are not mutually exclusive, but at least partly explained by or mediated through the other on the risk of MI. The mediating effect of income is independent of the choice of an income indicator. Income is not a big contributor to inequality in $\mathrm{Ml}$; probably because of the rather even income distribution in Denmark.
\end{abstract}

$\mathrm{S}$ tudies on the association between social position and myocardial infarction (MI) have consistently shown social differentials independent of whether social position is measured by education, occupation, or income. None the less, the indicators are not interchangeable. Each indicator has its own merit, and probably reflects common impacts of a general social stratification in a specific society as well as different dimensions specific to each indicator. ${ }^{1-5}$ Therefore the exact relation between health and social position may differ across societies and depend on which indicator is used. As an example the relation between income and self rated health (SRH) may differ among countries. ${ }^{67}$ Danish men experience a strong positive health effect of income up to US\$40 000 in equivalent household income, but no further effect occurs above that level of income, whereas men in Norway and Finland experience an improvement in SRH also at the high levels of income. ${ }^{6}$

The different indicators have causal and mediating relations. The health effect of education depends on which types of occupations are open to people with that type of education and the effect of occupation depends, among other things, on the income of the occupation and the person. ${ }^{8}$ Figure 1 shows the assumed causal relation between the indicators.

One methodological question in studies on income relates to the source of income information as well as the type of income measurement used. Studies based on self reported income are at risk of misclassification compared with register based information on income. ${ }^{39}$ Type of income is measurable in various ways associated with different potential mechanisms as status in the hierarchical ranking compared with consumption: gross household income (GHI) defines the total purchasing power of the household, whereas equivalent income (EI) takes household size and composition into account and thus shows the amount left after household expenses. Individual income (II) better corresponds to individual social status represented by income. Some authors have argued that the choice of income indicators does not matter, as the conclusions about income and health would not be changed. ${ }^{10}$ Others argue that EI should be chosen. ${ }^{11-13}$ The three ways of measuring income overlap. Nevertheless, the potential different effects require further exploration. Only a few studies, however, discuss the implications of different income indicators. Furthermore, the income inequalities in Denmark are especially low and this gives additional reasons to study the mediating role of income.

In general, studies on social position and health select one of the three social indicators and use this one as proxy for social position neglecting or treating the others as confounders. Few studies have addressed the causal relation between the various social indicators ${ }^{8}$ and explicitly examined the mediating effect of income on MI. ${ }^{14}{ }^{15}$ Mostly these studies are cross sectional using broad end points as SRH. The aims of this prospective study are to evaluate the role of income in mediating the effect of social position, measured as occupational class on incident MI, and to investigate whether the choice of income measurement affects the mediating effect.
Abbreviations: $\mathrm{BMI}$, body mass index; $\mathrm{ECM}$, employment classification module; El, equivalent income; $\mathrm{GH}$, gross household income; $\mathrm{HR}$, hazard ratio; II, individual income; ISIC, international standard classification of all economic activity; Ml, myocardial infarction; MONICA, monitoring trends and determinants in cardiovascular diseases; PALT, physical activity in leisure time; SBP, systolic blood pressure; $\mathrm{SRH}$, self rated health 


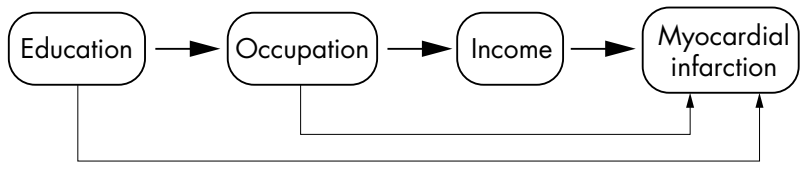

Figure 1 Pathways between socioeconomic determinants of health.

\section{METHODS}

\section{Study population}

The study is based on data from three population based cohort studies, conducted in Copenhagen, and combined in the Copenhagen Centre for Prospective Population Studies: the Copenhagen city heart studies, ${ }^{16}$ the Copenhagen male study, ${ }^{17-19}$ and the Glostrup population studies. ${ }^{2021}$ The studies have been described previously. ${ }^{22}$

Eligible for this study were employees aged 20-75 years, in total 17496 subjects. A total of 831 subjects were excluded because of missing information on the following key variables: income, tobacco, physical activity, alcohol, blood pressure, cholesterol, or body mass index (BMI). Other exclusions were caused by migration, MI, or death before start of follow up. This resulted in a study population of 16665 subjects: 7109 women and 9556 men. The study covered a total of 213450 person years and included 855 cases of MI.

\section{Data on social position}

In this study, social position was assessed by occupation. Only people employed at the time when occupation was registered were included. Employees were divided into five positions according to occupation and position at work. The positions are closely related to level of education required for each position.

Information on occupation was obtained via a linkage between the individual civil registration number and the employment classification module (ECM). ECM includes all citizens above 16 years with taxable income. ${ }^{23}$ All occupations are coded according to the ISIC (international standard classification of all economic activity), version 1968. We obtained the ISIC coding for each subject for every year from 1980 to 1996. For subjects examined from 1974 to 1984, we used codes from 1980. For subjects examined from 1985 to 1989 and 1990 to 1992, we used the codes from 1985 and 1990, respectively.

\section{Data on income}

The study population was linked via the person identification number to registers on Socioeconomic Information in Statistics Denmark. Information on income and family type were obtained for study participants and the cohabiting adult for the years 1980, 1985, and 1990. We used information on income from the same year as information on occupation.

Information on annual gross household income (GHI) was obtained from the Register of Income Statistics for each study participant and their cohabitant. GHI comprises all income types subject to taxation (wages and salaries, all types of benefits and pensions, net surplus or deficit, interest and share dividends).

We calculated GHI as the sum of the person's and cohabitant's gross income. We also wanted to investigate the effect of the gross individual income (II), and hence used the income of the study participant. Income was corrected for inflation since 1980 using the appropriate adjustments from Statistic Denmark's price index. Income was expressed in 1995 prices. In 1995, 10 DKK were considered equal to $£ 1 .{ }^{24}$ By contrast with the GHI, which shows the consumer power of the household, the goal of using equivalent income (EI) is to adjust for the number of family members that are dependent on the income. The EI is calculated on the basis of GHI by dividing GHI with a scale (e). The scale $(e)$ used in this study is based on the Danish Ministry of Finance and is as follows ${ }^{12}$ :

$$
(e)=[\mathrm{nA}]^{0.8}+0.5 \times[\mathrm{nC}]^{0.8}
$$

$\mathrm{nA}$ refers to number of adults and $\mathrm{nC}$ to number of children younger than 19 years in the family. A family is defined as consisting only of two adults.

Based on initial analyses of the effect of income in deciles on MI, the income measurements GHI, II, and EI were categorised into four groups (deciles 1-2, 3-5, 6-8, and 9-10) which were used in the final models.

\section{Confounding/mediating exposures}

In the cohorts, a broad range of well known contributing causes of MI were assessed for each participant at each examination using self administered questionnaires, clinical examinations, and blood samples. Although the phrasing of questions differed slightly in various sub-cohorts, it was possible to achieve sufficient consistency among the covariates used for this investigation.

- Smoking behaviour was determined using questions that categorise smokers according to their present tobacco consumption. Current smoking status was categorised into five groups according to the rate of tobacco consumption: never, former, 1-14, 15-24, $\geqslant 25 \mathrm{~g} /$ day.

- Alcohol consumption was categorised into four groups: none, $1-2,3-5,>5$ drinks/day.

- Physical activity in leisure time (PALT) was divided into three groups, measured in hours per week: none/little, moderate $2-4$ hours, moderate $>4$ hours/hard work $2-4$ hours/competition, hard work $>4$ hours.

The participants underwent a health examination with anthropometrical measurements and various laboratory tests.

- Body mass index (BMI), based on data collected by trained nurses, was calculated as weight in kilograms divided by height in metres squared and categorised into five groups: $<22,22-24,25-27,28-32,>32$.

- Systolic blood pressure (SBP) and blood lipids measured as total cholesterol, were divided into quintiles within cohorts, to avoid systematic errors in measurement among the cohorts.

Information on risk factors was collected at baseline and control for changes in risk factors during follow up was not undertaken in the main analysis. Information on cohabitation was obtained from registers. People were defined as cohabiting if they were married or lived with another adult person.

\section{Follow up}

Subjects were examined during 1974-1992, and were followed up for MI incidence until 31 December 1999. The first linkage between the study population and the register data was in 1980. Consequently, the follow up started in 1981 or at study entry, whichever was latest. It seems as if the increased risk of developing MI does not develop rapidly, such as after reporting loss of job control, but increases gradually over time. ${ }^{25}$ As we were concerned with the mediating effect of income between occupation and MI, subjects were censored five years after retirement, which occurred at age 67 . The subjects who continued to work after 67 were censored at age 75 years. 
Table 1 Baseline characteristics, subjects by occupational groups in the Copenhagen Centre for Prospective Population studies

\begin{tabular}{|c|c|c|c|c|c|c|}
\hline & & $\begin{array}{l}\text { Executive } \\
\text { managers/ } \\
\text { academic } \\
n=2275\end{array}$ & $\begin{array}{l}\text { Leading } \\
\text { managers } \\
n=2742\end{array}$ & $\begin{array}{l}\text { Salaried } \\
\text { employee } \\
n=5312\end{array}$ & $\begin{array}{l}\text { Skilled workers } \\
n=2107\end{array}$ & $\begin{array}{l}\text { Unskilled workers } \\
n=4229\end{array}$ \\
\hline Women & $\%$ & 15.0 & 35.6 & 65.0 & 5.1 & 52.8 \\
\hline Myocardial infarction & number & 130 & 151 & 209 & 142 & 223 \\
\hline Gross household income $<225000$ DKK & $\%$ & 5.1 & 11.5 & 24.7 & 15.0 & 31.9 \\
\hline Individual gross income $<150000$ DKK & $\%$ & 2.3 & 7.7 & 23.8 & 4.5 & 34.7 \\
\hline Equivalent income $<150000$ DKK & $\%$ & 7.7 & 14.3 & 22.1 & 22.5 & 32.9 \\
\hline Mean age & years & 52.3 & 50.0 & 48.3 & 49.9 & 49.0 \\
\hline Heavy smokers: $>15 \mathrm{~g} /$ day & $\%$ & 32.6 & 32.2 & 33.9 & 42.1 & 40.8 \\
\hline Alcohol: $>5$ drinks/day & $\%$ & 4.0 & 3.2 & 2.1 & 7.7 & 5.5 \\
\hline Physical activity: none/little & $\%$ & 14.6 & 16.8 & 19.7 & 16.1 & 24.9 \\
\hline $\mathrm{BMI} \mathrm{kg} / \mathrm{m}^{2} \geqslant 32$ & $\%$ & 2.4 & 3.7 & 3.9 & 4.7 & 7.1 \\
\hline SBP (mean) & $\mathrm{mm} \mathrm{Hg}$ & 128 & 126 & 125 & 129 & 129 \\
\hline Cholesterol (mean) & $\mathrm{mmol} / \mathrm{l}$ & 6.0 & 6.0 & 6.0 & 6.1 & 6.0 \\
\hline Education ( $<8$ years) & $\%$ & 9.4 & 24.6 & 32.3 & 49.6 & 63.0 \\
\hline Living alone & $\%$ & 20.9 & 27.1 & 32.3 & 20.5 & 29.1 \\
\hline
\end{tabular}

\section{End point}

The end point was defined as the first incidence of fatal or non-fatal MI. The cause of death was obtained from the National Death Register and cases of inpatient care for acute MI were obtained from the National Hospital Discharge Register. MI was defined according to the International Classification of Diseases: 8th revision code 410, and 10th revision codes I21-I22. Validity studies of the data in The National Hospital Discharge Register on MI have shown that they are sufficiently reliable. ${ }^{26}$

\section{Statistical methods}

The association between risk factors and incidence of MI was analysed using Cox's proportional hazards regression with age as the underlying time scale. A basic Cox model was developed that included GHI, II, and EI, respectively divided in four groups, with adjustment for cohort of investigation and marital status. A second model was developed that included occupational groups with adjustment for cohort of investigation, and marital status. In a third model, we tested the effect of including occupation into the income model and reverse. Lastly, the covariates tobacco, alcohol, PALT, SBP, cholesterol, and BMI were each entered separately as categorical covariates, as described above. The proportional hazards assumption was evaluated for all variables by comparing the estimated log-log survivor curves over the different categories of variables being investigated, and by tests based on the generalisation of Grambsch and Therneau. ${ }^{27}$ All covariates were tested for an interaction with social position and income by means of the likelihood ratio test. We found no interaction defined as departure from multiplicativity. The mediated proportion is calculated by

$$
100 \times \frac{H R_{\text {Unadj }}-H R_{\text {Adj }}}{H R_{\text {Unadj }}-1} \%
$$

Initial survival analyses were carried out separately for women and men. As the associations were similar, and the power for analysing women separately too small, all analyses were founded on pooled data, in a model permitting different baseline hazards for women and men. Statistical analysis was performed using Stata for Windows version 8 (StataCorp, College Station, TX).

\section{RESULTS}

During follow up, 855 subjects experienced an MI: 708 men, 147 women, and 402 events (47\%) were fatal. Table 1 gives the baseline data of the study population by socioeconomic position. The data do not show a clear social gradient for all covariates, mainly because of the skilled workers. In this group, a smaller proportion belongs to the lowest GHI and II groups compared with salaried employees. A larger

Table 2 Income and risk of myocardial infarction. Hazard ratios (95\% confidence intervals) of myocardial infarction by gross household, gross individual, and equivalent income based on 9556 men and 7109 women from the Copenhagen Centre for Prospective Population study

\begin{tabular}{|c|c|c|c|c|}
\hline DKK 1000 & Cases & Gross household * & Gross household † & Gross household ¥ \\
\hline$>465$ & 144 & 1 & 1 & 1 \\
\hline $350-465$ & 238 & 1.06 (0.86 tol.30) & $0.98(0.79$ to 1.22$)$ & 0.90 (0.73 to 1.12$)$ \\
\hline $225-350$ & 323 & 1.32 (1.07 to 1.61$)$ & $1.19(0.96$ to 1.48$)$ & 1.09 (0.88 to 1.35$)$ \\
\hline$<225$ & 150 & $\begin{array}{l}1.43 \text { (1.12 to } 1.83) \\
\text { Gross individual * }\end{array}$ & $\begin{array}{l}1.26 \text { (0.96 to } 1.64) \\
\text { Gross individual } t\end{array}$ & $\begin{array}{l}1.11 \text { (0.85 to } 1.44) \\
\text { Gross individual } \ddagger\end{array}$ \\
\hline$>300$ & 187 & 1 & 1 & 1 \\
\hline $300-225$ & 287 & $1.07(0.89$ to 1.29$)$ & 0.97 (0.79 to 1.19$)$ & 0.91 (0.74 to 1.11$)$ \\
\hline $225-150$ & 294 & 1.35 (1.12 to 1.64$)$ & $1.18(0.94$ to 1.47$)$ & $1.05(0.84$ to 1.31$)$ \\
\hline \multirow[t]{2}{*}{$<150$} & 87 & $1.48(1.10$ to 1.98$)$ & $1.26(0.92$ to 1.73$)$ & $1.17(0.85$ to 1.61$)$ \\
\hline & & Equivalent income* & Equivalent income $\dagger$ & Equivalent income $\ddagger$ \\
\hline$>250$ & 175 & 1 & 1 & 1 \\
\hline $200-250$ & 223 & $1.21(0.99$ to 1.47$)$ & $1.14(0.93$ to 1.40$)$ & $1.06(0.86$ to 1.30$)$ \\
\hline 150-199 & 298 & 1.51 (1.25 to 1.82$)$ & 1.40 (1.15 to 1.71$)$ & 1.32 (1.08 to 1.61$)$ \\
\hline$<150$ & 159 & $1.27(1.02$ to 1.58$)$ & $1.16(0.92$ to 1.46$)$ & $1.10(0.88$ to 1.39$)$ \\
\hline
\end{tabular}

*Adjusted for cohort of investigation, age, cohabitation, and sex. †Adjusted for occupation, cohort of investigation, age, cohabitation, and sex. $\ddagger$ Adjusted for cohort of investigation, age, cohabitation, occupation, tobacco, alcohol, physical activity, body mass index, systolic blood pressure, cholesterol, and sex, as described in the text. 
Table 3 Occupational group and the mediating effect of three measures of income divided into four groups. Hazard ratios $195 \%$ confidence intervals) of myocardial infarction by occupational group based on 9556 men and 7109 women from the Copenhagen Centre for Prospective Population studies

\begin{tabular}{|c|c|c|c|c|c|}
\hline & Basic model * & Basic model+GHI & Basic model + II & Basic model + El & $\begin{array}{l}\text { Basic model+ risk } \\
\text { factors } \dagger\end{array}$ \\
\hline Executive managers & 1 & 1 & 1 & 1 & 1 \\
\hline Leading managers & 1.23 (0.97 to 1.55$)$ & 1.18 (0.93 tol. .50$)$ & 1.21 (0.94 to 1.54$)$ & 1.16 (0.91 to 1.47$)$ & $1.18(0.94$ to 1.50$)$ \\
\hline Salaried employees & 1.34 (1.07 to 1.68 ) & 1.25 (0.98 to 1.59$)$ & 1.26 (0.97 tol.63) & 1.23 (0.97 to 1.56$)$ & 1.23 (0.98 to 1.54$)$ \\
\hline Skilled workers & 1.21 (0.95 to 1.53 ) & 1.13 (0.88 tol. .45$)$ & 1.16 (0.89 to 1.51$)$ & 1.11 (0.86 to 1.42 ) & 1.13 (0.89 to 1.44$)$ \\
\hline Unskilled workers & 1.55 (1.24 to 1.93 ) & 1.42 (1.12 to 1.81$)$ & 1.42 (1.10 tol.84) & 1.40 (1.11 to 1.78 ) & 1.32 (1.05 to 1.66$)$ \\
\hline
\end{tabular}

*Adjusted for cohort of investigation, age, cohabitation, and sex, as described in the text. †Adjusted for cohort of investigation, age, cohabitation, tobacco, alcohol, physical activity, body mass index, systolic blood pressure, cholesterol, and sex, as described in the text.

proportion of skilled workers are heavy smokers and drinkers compared with the unskilled workers.

Initial analyses of the association between GHI, II, and EI and risk of MI (table 2) show a clear income gradient in the risk of MI. The gradient is slightly steeper for II compared with GHI. EI showed a "reversed J shape" effect with highest HR for the third income group compared with the highest. When occupational group is included in the simple model, the estimates are attenuated, but significance remains only for the third EI group. Occupational groups explain 40\% of the increased risk among GHI low income groups. After adjustment for all risk factors, the income gradient almost disappears. However, it remained significant for the third EI group.

Initial analyses of the association between occupational groups and risk of MI, adjusted for sociodemographic confounders (table 3) show a social gradient in the risk of MI. When income is included in the model, the estimates remain significant only for unskilled workers. The mediating effect of income is independent of the method of measuring income, and is similar in strength for all three measures of income. Adjusting for GHI reduced the HR of unskilled workers to 1.42 (95\% CI 1.12 tol.81). Therefore in this group, adjustment mediated $24 \%$ of the increased risk. The explained fraction when cardiovascular risk factors, but not income, were included in the model was $42 \%$. When cardiovascular risk factors and GHI were simultaneously included in the model, the HR for unskilled workers compared with executive managers was reduced to 1.28 (95\% CI 1.00 tol.63 (results not shown).

\section{DISCUSSION}

This study shows that there is an effect of income on incident MI. The gradient in the risk of MI differs for EI compared with gross incomes. The effect is much weaker after adjustment for occupational grade. A small part of occupational differences in the risk of MI is mediated by income. Furthermore, the study shows that the mediating effect of income is independent of the choice of an income indicator in a Danish context.

\section{Key points}

- The production of social inequality in MI depends on interrelations among various socioeconomic indicators.

- There is no single "best" socioeconomic indicator.

- Parts of the effects of each socioeconomic indicator can either be explained by or mediated through other socioeconomic indicators.

- The mediating effect of income is independent of the choice of income indicator.

\section{Policy implications}

Low income inequalities seem to diminish the effect of income on the risk of MI.

\section{Choice of income indicator}

Mixed results regarding the strength and shape of the association between income and health are usually attributed to studies being incomparable because of the use of different income indicators as well as broad end points such as SRH. ${ }^{611}{ }^{1328}$ Our study shows that the association between income and MI is similar in direction and strength, independent of the income indicator used except for the lowest quartile of EI. Compared with those in the third quartile of EI, those in the fourth have a lower risk of MI. This result is similar to findings in other studies. ${ }^{6}{ }^{13} 28$ There are, however, potential biases that may generate this result. One explanation could be if these people have a higher income than reported in the registers. This result is potentially sensitive to how EI is calculated. One assumption of calculating EI is that children cost less than that of adults and this remains similar throughout childhood and adolescence. A second possibility is that the benefits of a large household are underestimated. To account for this we attempted to give each person in the household the same value (1). This lowered the income and attenuated the results, but the shape of the relation remained the same (results not shown). A third assumption is that the equivalent factor is similar for all levels of income, which is unlikely and difficult to account for. ${ }^{12}$ This discussion questions the advantage of using EI rather than GHI and emphasises that theoretical considerations should guide the selection of an indicator. ${ }^{10}$ The fact that income, independent of the measurement used, mediates only part of the occupational difference does not support that purchasing power is more important than hierarchical ranking or vice versa. Rather it emphasises the necessity of exploring processes between occupational grade, income, and MI that are not related to basic consumption. These include neomaterial conditions such as negative exposures and lack of individual ressources, psychosocial processes, social participation, relative deprivation besides those related to hierarchical ranking in the social structure..$^{29} 30$

\section{Small income inequalities}

The effect of income depends both on the exposure contrast generated by the income inequality and on the role of potential effect modifiers protecting against the effects of income. These include welfare policies aimed at reducing the duration of poverty, adverse housing conditions, poor nutrition, etc, linked to low income. A study comparing 
income related SRH in nine industrialised countries found a fairly clear correlation $(r=-0.87)$ between the ill health concentration index and the Gini coefficient. ${ }^{7}$ Figures from The OECD show, that Denmark, with a Gini coefficient around 22 in the 1990s was the country with the smallest income inequality. In our study, income mediates only a small part of the occupational difference. This may be because of a low Gini coefficient, but it is also dependent on the cut off point used to define income groups. ${ }^{31}$

\section{Confounders/mediators}

Information on occupation and income was collected at the same point in time, which makes it possible to show in table 2, that if including occupation in the model, at least part of the effect of income is confounded by occupation. As illustrated in figure 1 , we assume that income is on the causal pathway from occupation to MI. Table 3 shows the proportion of the effect mediated by income is similar for all three measures of income. However, the mediated proportion is smaller than in other studies, ${ }^{8} 15$ which may be explained by the small wage range in Denmark and the moderating effect of its welfare state. For most of the cohorts, information on cardiovascular risk factors, which seems to be related to social position and also to be a cause of MI, was collected earlier in time than information on occupation and income, and may therefore primarily be seen as confounders. However, these covariates tend to track over the life course and thus may also work as mediators. If cardiovascular risk factors are treated as causal intermediates between income and MI adjusted for occupation, then table 2 shows that a large part of the income difference disappears except for EI group 3. The explained fraction when cardiovascular risk factors, but not occupation, were included in the model was similar to the proportion explained by occupation (data not shown).

\section{Income measured only once}

A potential limitation of our study design is that income was measured only at one point in time. To fully understand the impact of income, it may be important to account for income dynamics. ${ }^{32}$ Long term poverty may have a different impact on health than short term poverty. A British cross sectional study found that long term income is more important for health than current income, and that income levels are more important than income change. ${ }^{33}$ Lifetime salaries are more equal than salaries for a single year, ${ }^{33}$ which means that we may underestimate the effects attributable to non-differential misclassification. About $3.6 \%$ of the Danish population remains in poverty (defined as being below $70 \%$ of the median income) as assessed by life incomes. ${ }^{34}$ Additionally, income inequality may differ during follow up. However, recent data show that the relative difference between occupational social groups was stable during the study period. $^{35}$

\section{Only employees}

The study includes employees, excluding those without employment, self employed, and employers. This may reduce the range of contrast in the study. However, it needs to be considered that income information from the excluded groups may be less reliable. Strengths of this study is that we used valid register based information and a well defined end point.

\section{Conclusion}

This study, using register based information on income as well as valid MI incidence, shows that both occupation and different income measures have an effect on the risk of MI. The effect of occupation is at least partly mediated by income.
The study confirms other results that have shown that income is not a big contributor to inequality in health in Denmark. This is probably attributable to the rather even distribution of income in Denmark.

\section{Authors' affiliations}

I Andersen, M Gamborg, E Prescott, Copenhagen Centre for Prospective Population Studies, Danish Epidemiology Science Centre, at the Institute of Preventive Medicine, H:S Kommunehospitalet, Copenhagen University Hospital, Copenhagen, Denmark

M Osler, F Diderichsen, Copenhagen Centre for Prospective Population Studies, at the Institute of Public Health, Copenhagen University, Copenhagen

E Prescott, Department of Cardiology, Rigshospitalet, Copenhagen

Funding: this study was supported by a grant from Copenhagen Hospital Corporation and by the Danish Heart Foundation.

Conflicts of interest: none.

\section{REFERENCES}

1 Grusky DB. The contours of social stratification. In: Social stratification in a sociological perspective. Class, race, and gender. Oxford: Westview Press, 1994:3-35

2 Sørensen A. The basic concepts of statification research: class, status, and oower. In: Grusky DB, ed. Social stratification in sociological perspective. Class, race, and gender. Oxford: Westview Press, 1994:229-41.

3 Liberatos P, Link BG, Kelsey JL. The measurement of social class in epidemiology. Epidemiol Rev 1988;10:87-121.

4 Lynch J, Kaplan GA. Socioeconomic position. In: Berkman L, Kawachi I, eds. Social epidemiology. Oxford: OUP, 2000:13-35.

5 Martikainen P, Bartley M, Lahelma E. Psychosocial determinants of health in social epidemiology. Int J Epidemiol 2002;31:1091-3.

6 Mackenbach J, Martikainen P, Looman P, et al. The shape of the relationship between income and self-assessed health: an international study. Int $J$ Epidemiol (in press).

7 van Doorslaer $E$, Wagstaff A, Bleichrodt $\mathrm{H}$, et al. Income-related inequalities in health: some international comparisons. J Health Econ 1997;16:93-112.

8 Lahelma E, Martikainen P, Laaksonen M, et al. Pathways between socioeconomic determinants of health. J Epidemiol Community Health 2004;58:327-32.

9 OECD. Trends and driving factors in income distribution and poverty in the OECD area. London: OECD, 2000.

10 Kawachi I, Kennedy BP. The relationship of income inequality to mortality: does the choice of indicator matter? Soc Sci Med 1997;45:1121-7.

11 Rahkonen O, Arber S, Lahelma E, et al. Understanding income inequalities in health among men and women in Britain and Finland. Int J Health Serv 2000;30:27-47.

12 Jørgensen S. Analyser af indkomstfordeling. [Analysis on the distribution of income]. Copenhagen: Det Økonomiske Råds Sekretariat, 2001.

13 Fritzell J, Nermo M, Lundberg $O$. The impact of income: assessing the relationship between income and health in Sweden. Scand J Public Health 2004;32:6-16.

14 Virtanen SV, Notkola V. Socioeconomic inequalities in cardiovascular mortality and the role of work: a register study of Finnish men. Int J Epidemiol 2002;31:614-21

15 Yngwe MA, Diderichsen F, Holland P, et al. The role of income differences in explaining social inequalities in self rated health in Sweden and Britain. $J$ Epidemiol Community Health 2001;55:556-61.

16 Appleyard M, Hansen A, Schnohr P, et al. The Copenhagen City heart study. A book of tables with data from the first examination (1976-8) and a 5-year follow-up (1981-3). Scand J Soc Med 1981;170:1-160.

17 Suadicani P. Identification of risk factors mediating the excess risk of ischaemic heart disase in low social classes. (MD thesis). Copenhagen: Copenhagen University, 2002

18 Gyntelberg F. Koronar hjertesygdom og fysisk aktivitet, epidemiologiske studier til belysning af sammenhængen mellem fysisk aktivitet og risiko for koronar hiertesygdom. [Coronary heart disease and physical activity, epidemiological studies to elucidate the association between physical activity and coronary heart disease]. (MD thesis). Copenhagen: Københavns Universitet, 1975.

19 Hein HO, Suadicani P, Gyntelberg F. Alcohol consumption, serum low density lipoprotein cholesterol concentration, and risk of ischaemic heart disease: six year follow up in the Copenhagen male study. BMJ 1996;312:736-41.

20 Hagerup L, Schroll M, Hollnagel H, et al. The Glostrup population studies. Collection of epidemiologic tables. Reference values for use in cardiovascular population studies. Scand J Soc Med 1981;20:1-112.

21 Schroll M. The World Health Organisation MONICA project (monitoring trends and determinants in cardiovascular disease): a major internationa collaboration. J Clin Epidemiol 1988;41:105-14.

22 Andersen I, Burr H, Kristensen TS, et al. Do factors in the psychosocial work environment mediate the effect of socioeconomic position on the risk of myocardial infarction? Study from the Copenhagen Centre for Prospective Population Studies. Occup Environ Med 2004;61:886-92. 
23 Andersen O, Laursen L, Petersen J. Occupational mortality 1981-1995. Copenhagen: Statistics Denmark, 2002.

24 Danmarks Statistik. Statistisk tiårsoversigt 1996. [Statistical ten-year review] Copenhagen: Statistics Denmark, 1997

25 Theorell T, Tsutsumi A, Hallquist J, et al. Decision latitude, job strain, and myocardial infarction: a study of working men in Stockholm. The SHEEP study Group. Stockholm heart epidemiology program. Am J Public Health 1998;88:382-8.

26 Madsen M, Davidsen M, Rasmussen S, et al. The validity of the diagnosis of acute myocardial infarction in routine statistics: a comparison of mortality and hospital discharge data with the Danish MONICA registry. J Clin Epidemiol 2003;56:124-30.

27 Grambsch PM. Proportional hazards tests and diagnostics based on weighted residiuals. Biometrika 1994:81:515-26.

28 Ecob R, Smith GD. Income and health: what is the nature of the relationship? Soc Sci Med 1999;48:693-705.

29 Lynch JW, Davey Smith G, Kaplan GA, et al. Income inequality and mortality: importance to health of individual income, psychosocial environment, or material conditions. BMJ 2000;320:1200-4.
30 Stronks K, van de Mheen HD, Mackenbach JP. A higher prevalence of health problems in low income groups: does it reflect relative deprivation? $J$ Epidemiol Community Health 1998;52:548-57.

31 Ditlevsen S, Christensen U, Lynch J, et al. The mediation proportion: a structural equation approach for estimating the proportion of exposure effect on outcome explained by an intermediate variable. Epidemiology 2005; 16:114-20.

32 Beebe-Dimmer J, Lynch JW, Turrell G, et al. Childhood and adult socioeconomic conditions and 31-year mortality risk in women. Am J Epidemiol 2004;159:481-90.

33 Benzeval M, Judge K. Income and health: the time dimension. Soc Sci Med 2001;52:1371-90.

34 Finansministeriet $\mathbf{m}$. fl. Lavindkomstgruppen - mobilitet og sammensætning [The low-income group - mobility and composition]. Copenhagen: Schultz Information, 2004.

35 Andersen I, Tuchsen F, Diderichsen F, et al. Social factors and cardiovascular diseases. In: Videbæk J, Madsen M, eds. Heart statistics. Copenhagen: Danish Heart Foundation, National Institute of Public Health, 2004:7-93.

\section{THE JECH GALLERY}

\section{The words of the prophets}

Dublic health professionals are increas-

ingly engaged in evaluating knowledge and attitudes about health among populations and a variety of validated qualitative and quantitative methods are in use.

Graffiti-whether on subway walls, tenement halls, or on a bus shelter in Glasgow, UK (picture)-may also provide useful insights into public health concerns. "DON'T WORRY ABOUT FAT. ADDITAVES (sic) ARE THE REAL ENEMY" reflects how fears about new food technologies may be of greater concern than conventional public health nutritional priorities.

(The empty sand-timer is an advertisement that social benefits books are being withdrawn).

\section{Greater Glasgow NHS Board Dalian House, PO Box 15329, 350 St Vincent Street, Glasgow G3 8YZ, UK;} david.morrison@gghb.scot.nhs.uk

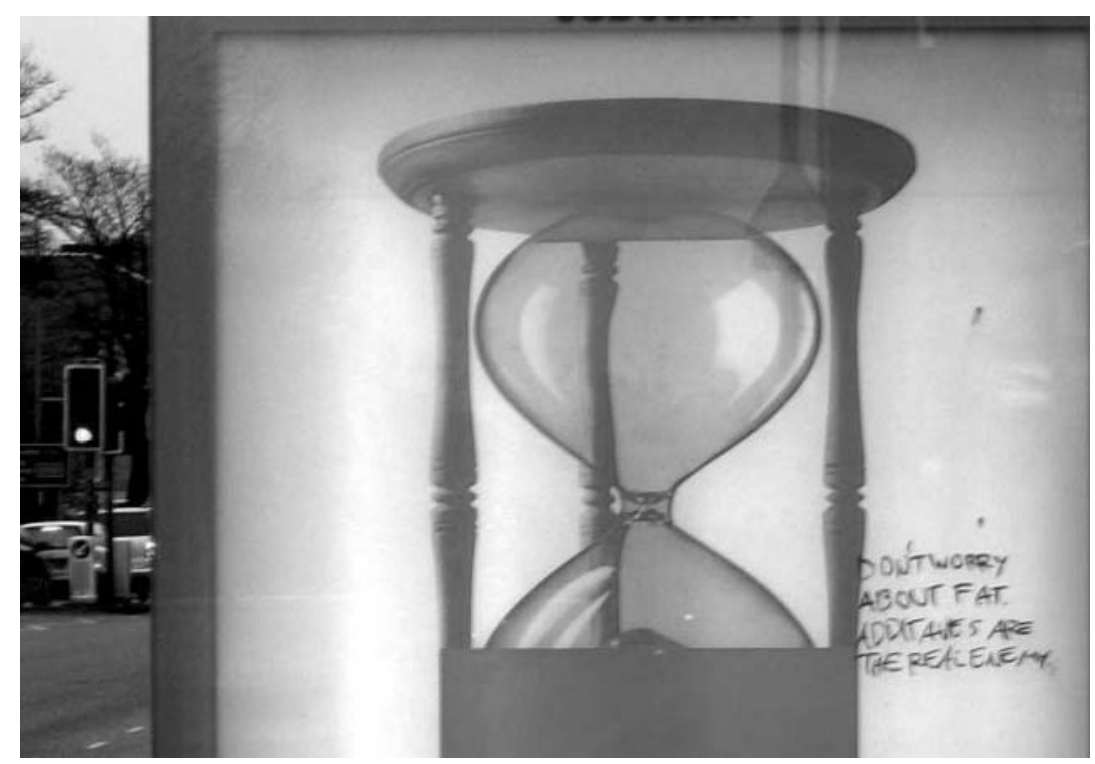

